\title{
New beginnings in post graduate medical education. Latin American Medical Education Leaders Forum
}

\author{
Nuevos comienzos en la educación médica de postgrado. \\ Foro Latinoamericano de Líderes en Educación Médica
}

Klaus Puschel ${ }^{1}$, Tai Telesco², Marcela Grez', Trinidad Hoyl'1, Luis Ibañez ${ }^{3}$, Oscar Casiro ${ }^{4}$

\begin{abstract}
Introduction: The consequences of the Covid-19 epidemic have been catastrophic for Latin America in 2021. This study explores experiences, lessons learned, and practice changes during this critical time in post-graduate medical education in Latin America. Methods: A panel of 53 post-graduate medical education leaders from 8 Latin American countries and Canada was invited to participate in the 2021 Latin American Medical Education Leaders Forum to share their experiences, lessons learned, and main educational practice changes given the Covid-19 pandemic scenario. Participants were selected following a snowball technique with the goal of obtaining a diverse group of experts. Small group discussions were conducted by bilingual facilitators based on a semi-structured questionnaire. The plenary session with the main conclusions of each group was recorded and fully transcribed for a thematic analysis using a framework methods approach. Results: Participants' profiles included 13 experienced clinician-educators, 19 program directors, and 23 deans or organizational representatives. Seven specific themes emerged. They followed a pattern that went from an initial emotional reaction of surprise to a complex collective response. The responses highlighted the value of adaptability, the application of new digital skills, a renovated residents' protagonism, the strengthening of humanism in medicine, the openness of new perspectives in wellness, and finally, an unresolved challenge of assessment in medical education in a virtual post-pandemic scenario. Conclusion: A diverse panel of medical educators from Latin America and Canada identified changes triggered by the Covid-19 pandemic that could transform postgraduate medical education in the region.
\end{abstract}

Keywords: post-graduate medical education; Latin America; Covid-19; international forum.

\section{Resumen}

Introducción: la pandemia de Covid-19 ha tenido consecuencias catastróficas para América Latina en el año 2021. Este estudio explora las experiencias, lecciones aprendidas y nuevas prácticas surgidas durante este crítico período en la educación médica de postgrado en América Latina. Métodos: un panel de 53 líderes de 8 países de América Latina y Canadá fue invitado a participar en el Foro Latinoamericano de Líderes en Educación Médica 2021 para compartir sus experiencias, lecciones aprendidas y cambios de prácticas educativas en el escenario de pandemia. Los participantes fueron seleccionados mediante la técnica de bola de nieve con el objetivo de obtener un grupo diverso de expertos. El Foro incluyó discusiones de pequeños grupos conducidos por facilitadores bilingües basadas en un cuestionario semiestructurado. La sesión plenaria con las principales conclusiones de los grupos fue grabada y transcrita para el análisis temático posterior utilizando la metodología de marco analítico. Resultados: el perfil de participantes incluyó 13 experimentados educadores, 19 directores de programa y 23 decanos o representantes institucionales. Siete tópicos emergieron durante la discusión. Ellos siguieron un patrón que transitó desde una reacción emocional de sorpresa por la pandemia hasta una respuesta colectiva compleja. Las respuestas enfatizaron el valor de la adaptabilidad, la aplicación de nuevas habilidades digitales, un renovado protagonismo de los residentes, el fortalecimiento del humanismo en medicina, la apertura a nuevas perspectivas de bienestar y, finalmente, un desafío

(1) Center of Health Sciences and Medical Education. Faculty of Medicine. Pontificia Universidad Católica de Chile. Santiago, Chile

(2) Royal College of Physicians and Surgeons of Canada. Ottawa, Canada

(3) Department of Gastrointestinal Surgery. School of Medicine. Pontificia Universidad Católica de Chile. Santiago, Chile

(4) Department of Pediatrics. Faculty of Medicine. University of British Columbia, British Columbia, Canada.

Corresponding author: kpuschel@med.puc.cl 
no resuelto respecto de la evaluación en educación médica en escenarios de pandemia. Conclusión: un panel diverso de educadores médicos latinoamericanos y canadienses identificó cambios claves gatillados por la pandemia de Covid-19 que pueden transformar la educación médica de postgrado en la región.

Palabras clave: educación médica de post-grado; América Latina; Covid-19, for internacional

Submission date: 2021-10-26 - Acceptance date: 2021-12-14

\section{Introduction}

The consequences of the Covid-19 epidemic have been especially catastrophic for Latin America in 2021. Six of the top ten countries with the highest mortality rates worldwide during June 2021 were from Latin America (Johns Hopkins Resource Center, 2021). Countries such as Argentina, Brasil, Chile, Mexico, and Peru have reported incidence rates for Covid-19 between 280 and 540 cases per million in June 2021, much higher than the 30 to 40 cases per million reported in the United States, Canada, or most Western European countries for the same period (Oxford Martin Programme on Global Development, 2021).

In this scenario, local communities have experienced an unbearable amount of suffering, medical services have been surpassed in most countries, and health care teams have been overstressed. Postgraduate medical programs had to navigate in this critical context and to adjust to conditions that have been never experienced before (Chasset et al., 2021).

The pandemic period found Latin American medical education in a very particular scenario. The region has experienced a significant increase in new medical schools and residency programs during the last decades. About 15\% of medical schools worldwide are from Latin America (Duvivier et al., 2014). Most of the residency programs are yet to start to systematize their training models (Duvivier et al., 2014; Hoyl et al., 2019)

Despite the high proportion of medical schools and residency programs in Latin America, there is a lack of information on the effects of the Covid-19 pandemic on post-graduate medical education in the region. In the systematic review conducted by Chasset et al. (2021) on the consequences of the Covid-19 pandemic on residents and medical students, the authors identified over 1400 references and included 60 articles in their final analysis; none of these articles were from Latin America. Similarly, Tolu LB et al. (2020) did not include any Latin American report in their scoping review of adaptive approaches for residency training during the Covid-19 pandemic.

This study reports the experiences, lessons learned and educational practice changes implemented on a large group of post-graduate medical programs across Latin America. A diverse group of experienced educators and organizational leaders gathered at the 2021 Latin American Medical Education Leaders Forum (IMELF-LA). The Forum is an international encounter where medical education leaders from Latin America and Canada discuss relevant trends and changes that could improve post-graduate medical education in the region. The Forum offered an opportunity to reconnect a community that has been strongly hit by the pandemic and allowed participants to analyze what experiences and themes have emerged and could make a significant impact on the organizations and communities they lead.

\section{Methods}

\section{Study setting and participants}

The IMELF-LA Forum was organized by the Centre of Medical Education at the Faculty of Medicine at Pontificia Universidad Católica de Chile (UC) and the Royal College of Physicians and Surgeons of Canada (RCPS). UC and the RCPS have organized two previous IMELF-LA encounters in 2017 and 2019 as part of a long collaborative experience in post-graduate medical education that began a decade ago. The topic of the 2021 Forum was: "New beginnings in post-graduate medical education: Lessons learned and what will remain".

Participation in the Forum was by invitation. A snowball technique was used to select participants. Leadership and diversity in residency education experiences were the main criteria considered to define the target group of participants. Three main groups were designed a priori to ensure a diverse group of leaders and experienced post-graduate medical educators. The first group included expert clinician-educators identified by their peers and local academic leaders. The second group included senior academic coordinators, post-graduate and medical school directors. The third group integrated deans, associate deans, and presidents or vice-presidents of national or international institutions.

\section{Procedures}

The Forum's program included three presentations, small group discussions, and an interactive plenary session. Presentations topics focused on student's health digital competencies in the pandemic 
scenario (Sonnenberg L. University of Alberta), distant simulation training with remote and asynchronous feedback (Varas J. Pontificia Universidad Católica de Chile), and, trans-pandemic residency education: dreams and challenges (Sanchez M. Universidad Nacional Autónoma de México). The small group discussion was based on a semi-structured brief questionnaire sent one week before the encounter to each participant. The questionnaire asked participants to reflect on a specific experience or situation related to postgraduate medical education during the pandemic and on what made that experience significant. It also explored participants' perceptions on what they could have done differently if they had time to plan residency education strategies before a pandemic situation. The final question asked participants to reflect on future changes in residency education that should be implemented during the next two years, given the pandemic experience.

Participants split into eight groups, and each of them was conducted by a bilingual facilitator who took field notes and summarized the information gathered during the discussion. Each group presented their reflections and conclusions at a plenary session. The plenary session was audio-video recorded and fully transcribed for the analysis.

\section{Analysis}

The analysis of the information was based on field notes taken by organizers and group facilitators, a review of the recorded sessions, and plenary session transcripts. A framework methods approach (Ritchie \& Lewis, 2003) was used to analyze the information. This approach is recommended when analyzing qualitative information explored within a specific topic. It has been used previously in similar contexts (Puschel et al., 2017). Key concepts were coded and clustered in common themes that were included in the general framework of the discussion that focused on the lessons learned in residency education given the pandemic scenario. The information was charted in a concept mapping developed to summarize the main findings.

The report was sent to all participants for their review. General comments on the document and specific suggestions or additions related to the results of this report were considered and included in the final version.

\section{Results}

The 2021 IMELF-LA Forum gathered 53 participants from 9 different countries. The first group of experienced clinician educators included 13 participants. The second group of senior academic coordinators, postgraduate and medical school directors, integrated 19 participants. The third group included 12 deans, four vice-deans or associate or assistant deans, two pro-rectors or vice-rectors, and three presidents or vice-presidents of national or international institutions. The participants' profile is presented in Table 1.
The results of the information were grouped into seven main themes. Each theme expressed a cluster of key-related concepts expressed during the discussions. Table 2 summarizes the themes and key concepts that emerged during the discussions.

\section{From surprise to chaos:}

The majority of groups expressed that the pandemic generated a first surprised reaction among their clinical and academic communities. It was a sudden event that appeared unexpectedly and irrupted in unprepared residency programs. Most teams had the idea that this was an acute event that would last a couple of weeks, and that was not going to affect them strongly. The sense of surprise turned into uncertainty, disorganization, and chaos in most programs. The exceptional event was transitioning into a permanent "abnormal" scenario. It was not clear what changes were needed to keep up with residency training, in what priority, and for how long. It was not clear how to proceed in this new scenario. The concept of chaos (khaos) emerged strongly in the discussion; it was related to concepts such as obscurity, disorganization, and emptiness.

\section{Adaptability as a new competence:}

Participants described several new strategies to adjust to the new pandemic scenario. Many faculty and residents got involved in activities not related to their specialties as a way to serve patients and local communities given the public health crisis. There was a sense of working in real-life situations. Paradoxically, the real-life scenario was new, unstable, and required flexibility and new adjustment skills. Willingness and abilities to work with other professionals, technicians, and community members in different fields of no personal expertise appeared as essential to serve better. Family physicians helping in intensive care units, ophthalmologists contributing to community testing, and infectious disease specialists working with community organizations were examples of real transdisciplinary work. Adaptability emerged as a new competence that included communication abilities, empathy, compassion, and openness to learning from others. Adaptability was seen as an essential competence to serve better.

Participants emphasized the teamwork approach of different medical specialists. They tried to contribute from their expertise, adapting their actions to the social reality. This experience revealed professionals as public servers, capable of responding in a non-familiar environment, distant from their specific work field.

\section{New digital skills:}

There was consensus among participants on the essential role of digital technology for enhance residency training. The pandemic crisis uncovered the opportunities and capabilities of technology to improve residency training, making it more effective and 
Table 1: Participants' profile.

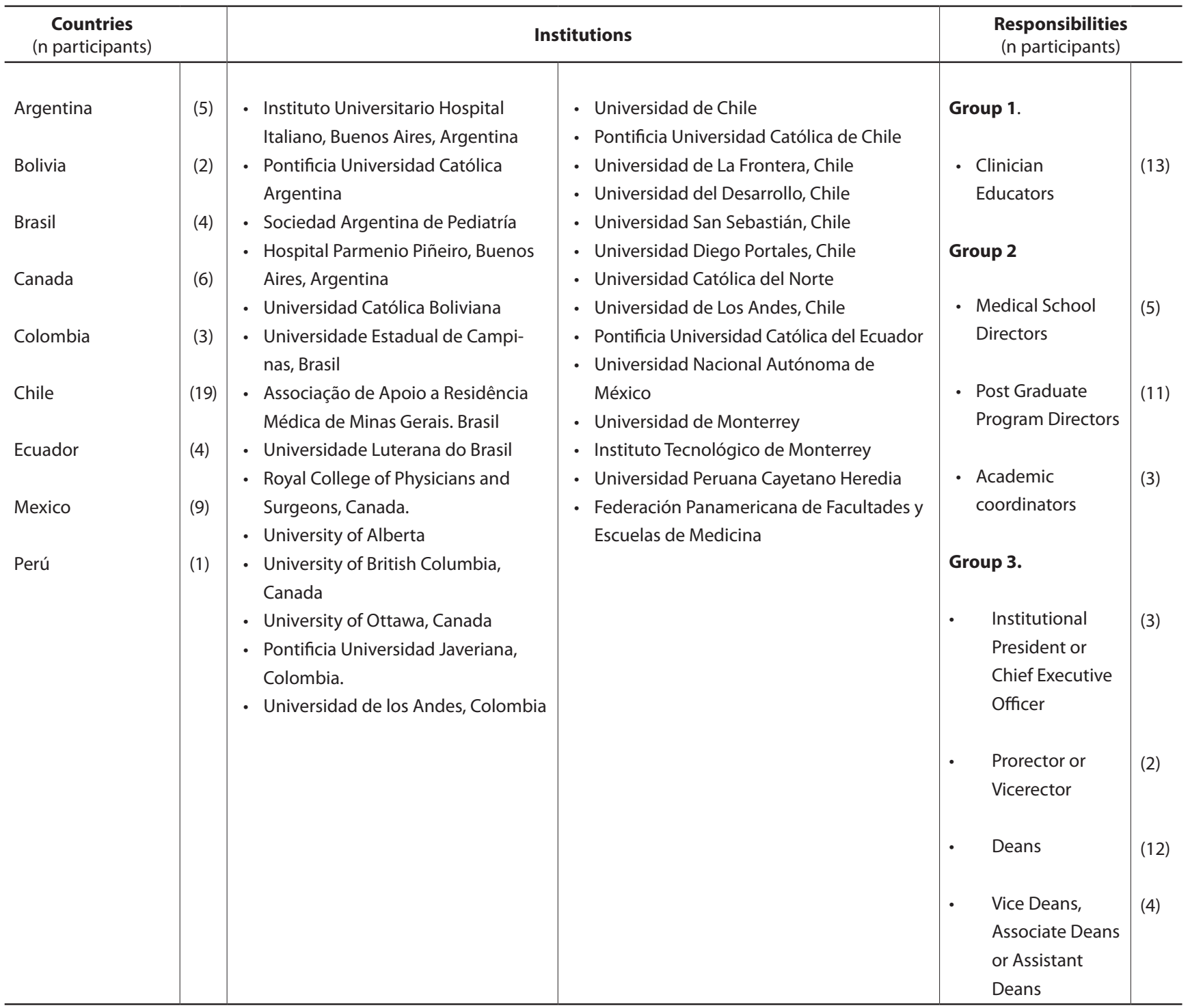

efficient. Application of digital technology to retake clinical consultations and supervision through telemedicine, workshops, and webinars via zoom for topic discussions and distant simulation training with virtual feedback were some of the digital education strategies mentioned by participants. Some of them emphasized that good traditional educators were also good digital educators, and therefore, educational principles remain the same. However, most participants agreed that digital skills were essential to take full advantage of technology and that there was a high, probably generational, variability in those skill levels among faculty. Many faculty gave examples of residents helping them to use technology appropriately. There was agreement that faculty should have consistent digital skills for residency training and that many will need to improve them in the new scenario after the epidemic.
Participants highlighted that technical information and communication (TICS) skills are here to stay in medical education and that the pandemic triggered this change. The change was "announced" years ago, but the pandemic boosted it in a short period and allowed the programs to sustain medical education during the crisis.

\section{New role of residents as protagonists:}

The traditional learner-centered approach acquired a new dimension during the pandemic scenario. Residents' less specific professional development allowed them to serve better as generalists in different highly demanded scenarios such as emergency care, community services, or primary care. In some cases, residents of a specific specialty (e.g., intensive care, primary care) had to supervise specialist faculty helping with clinical work in areas that were not of their 
expertise. In addition, residents' better digital skills allowed them to collaborate actively, and sometimes conduct training sessions directed for their peers. Many examples of faculty learning from residents, now in an explicit way, were mentioned. Residents helped faculty in telemedicine, virtual simulation, and virtual workshops (e.g., group sessions). Less directive education strategies and more emphasis on self-training were mentioned as a predominant model by some participants in this pandemic context. The facilitator role of the faculty was evident given the current scenario. A complimentary, probably more genuine, interaction between faculty and residents emerged in many cases during the epidemic crisis.

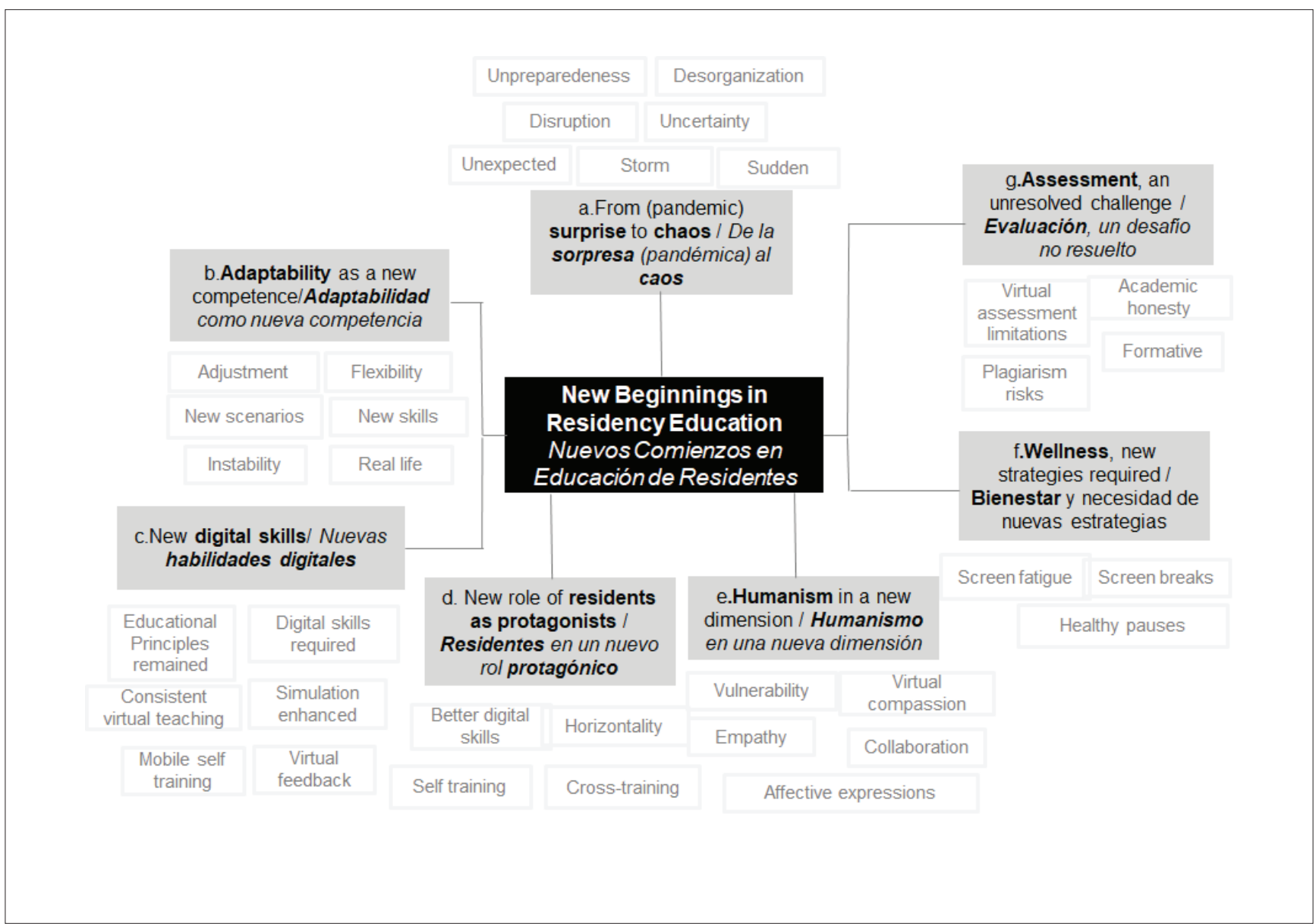

Figure 1: Main themes and key concepts.

\section{Humanism in a new dimension:}

Most participants mentioned that the community burden associated with the epidemic, not only for patients but also for health teams, peers, family, and close friends, highlighted the humanistic dimension of medicine. There was a consensus that life has changed for everybody. The traditional paternalistic and vertical approach of taking care of patients as part of the medical commitment was twisted (once again) by the epidemic that generated a sense of a vulnerable community that included patients and health care teams, family, friends, students, and faculty. Empathy and collaboration were translated from principles to practices, given the need for mutual care.

\section{Wellness, new strategies required:}

The relevance of wellness in residency education was emphasized by many participants in the Forum. However, there was agreement that the new learning scenario with digital strategies as the main component, the leading role of residents, and the sense of general vulnerability triggered by the epidemic, required new wellness strategies. Participants mentioned many new factors affecting the wellness of residents. Among them, mental health consequences of screen fatigue, the frustration of residents associated with fewer opportunities, for example, for doing procedures in clinical settings, and the lack of opportunities for social interaction in informal contexts. In a post-pandemic scenario, some of these factors will 
remain. Some of the strategies mentioned to face these factors were the development of mandatory healthy pauses and screen breaks, as well as the enhancement of voluntary support groups with protected time as part of the residency training programs.

\section{Assessment, an unresolved challenge:}

Most participants highlighted that virtual educational strategies were going to remain in a post-pandemic scenario, but there was concern on how to improve assessment of clinical and non-clinical competencies in this context. The evaluation of residents' skills in uncertain real clinical scenarios respecting patients' privacy, the interaction of residents with real health teams as well as the assessment of procedures in real contexts was seen as relevant components in residency training that are not fully captured yet in virtual education.

Academic dishonesty was an important concern raised by some participants that emphasized the higher risk of dishonest behaviors when evaluating the competencies of residents in virtual (synchronic or asynchronous) scenarios. Advances in educational technology, enhancement of self-centered learning strategies, and the need to strengthen self-responsibility and professionalism were some of the elements mentioned to improve assessment in virtual scenarios. However, there was consensus that this remains an unresolved challenge, and more experience and research is needed in this area for post-pandemic times.

\section{Discussion}

The diverse group of leaders that participated in the 2021 IMELFLA Forum identified profound changes in post-graduate medical education triggered by the pandemic. These changes were probably initiated before the epidemic but were activated and amplified by the catastrophic consequences of the Covid-19 disease. The changes identified were so profound that they predict a new beginning in post-graduate medical education in Latin America.

The sense of initial chaos (khaos) in residency training that emerged as a strong theme in the discussion of our Forum has also been highlighted in several editorials, commentaries, and reviews as an initial effect of the Covid-19 pandemic (Lucey et al.,2020; Rose et al., 2020; Trevor et al., 2020; Papapanou et al., 2021). It has been described as disruption and sudden confusion. Our panel added on the concept of disorganization, the image of a storm and the sudden (súbito) effect of the crisis. The concept of chaos (khaos) emerged in the discussion connected with its original Greek meaning i.e. as an obscure abyss, as "an emptiness that existed before things came into being" (Merrian Webster, 2021).
Our panel identified an empowering effect of residents due to the pandemic that was expressed in very concrete experiences. One example is their leading role in helping their faculty use digital technology effectively to improve educational activities. Virtual education strategies have been extensively described in many reports as an immediate response to maintaining medical education activities (Tolu et al., 2020; Chasset et al., 2021; Papapanou et al., 2021). However, the protagonist role of residents in this process has been less described. Another example is the resident's role in helping their faculty in general care practices required during the pandemic where residents had more recent experience due to their undergraduate training. This empowering effect of the pandemic, on residents could help to change a vertical tradition of medical education and enhance medical professionalism in Latin America (Puschel et al., 2017).

Medical humanism expressed by empathy, compassion, and collaboration in critical scenarios was highlighted as an essential value of medicine that was uncovered during the pandemic. Many Latin American faculty and residents participated as "frontline workers." Our panel identified the relevance of this experience to (re)connect with the core values of medicine but also recognized the mental health consequences of it. Exhaustive clinical work, new virtual educational scenarios, and physical distance were identified as strong risk factors for mental health problems. These factors have been described elsewhere (Papapanou et al., 2021). Given this scenario, the panel highlighted the need for new wellness strategies such as screen breaks, healthy pauses, and virtual support meetings to face these new challenges. There was agreement that humanism in medicine was not only an essential value to serve others with dignity but also a value that required self and collective care.

This study has some limitations that are important to address. First, it is a report from a selected panel of experienced medical educators and academic directors that might not represent the variety of experiences in residency education of the large Latin American community. To face this limitation, a snowball technique was used that aimed to include a diverse group of participants. A group of Latin American medical education leaders that has previously collaborated with the research team facilitated this process (Puschel et al., 2017). Second, the analysis of the information was based on secondary data from the reports of the group discussion and open plenary. Specific primary information from participants within the group discussion might have been missed using this strategy. However, a systematic approach using a semi-structured questionnaire to gather the information and a framework analysis approach to analyze the information was applied to standardize 
the information shared by participants. Credibility was ensured by member checking. All participants received a full report of the Forum and had the opportunity to review and make changes to it after the encounter.

This study opens new perspectives in post-graduate medical education. Future research should explore better assessment strategies in virtual clinical scenarios and look for innovative support interventions to enhance wellness in residency programs. In addition, the study highlights the relevance of conducting new research to understand better the way adaptability could be developed and assessed as competency in residency education.

\section{Conclusion}

The 2021 Latin American Medical Education Leaders Forum gathered a diverse group of experts and leaders in postgraduate medical education that highlighted seven key themes that emerged strongly during the covid-19 pandemic and anticipate a new beginning in residency education in the region.

\section{Contributions and acknowledgments}

We want to recognize the contribution of all the participants of the Latin American Forum of Leaders in Medical Education 2021 for the valuable experiences shared.

The Forum was funded by the Center for Medical Education and Health Sciences of the Faculty of Medicine of the Pontificia Universidad Católica de Chile.

The authors report no conflicts of interest.

\section{References}

Chasset F, Barral M, Steichen O. \& Legrand A. (2021). Immediate consequences and solutions used to maintain medical education during the COVID-19 pandemic for residents and medical students: a restricted review. Postgraduate Medical Journal. April $1^{\text {st }}$. postgradmedj-2021-139755. Advance online publication. Accedido en : https:// doi.org/10.1136/postgradmedj-2021-139755 el 30 de Agosto de 2021.

Duvivier RJ, Boulet JR, Opalek A, van Zanten M. \& Norcini J. (2014). Overview of the world's medical schools: an update. Medical Education 48, 860-869.

Johns Hopkins Coronavirus Resource Center (2021). Mortality in most affected countries. Accedido en: https://coronavirus.jhu.edu/ data/mortality el 21 de Junio de 2021.
Oxford Martin Programme on Global Development. University of Oxford (2021). Our world in data. Accedido en: https://www. oxfordmartin.ox.ac.uk/global-development/ el 21 de Junio de 2021.

Hoyl T, Riquelme A. \& Snell L. (Editorial). (2019) Latin American Conference on Residency Education: LACRE 2019 Ars Medica 44, 2-3.

Lucey CR. \& Johnston SC. (2020). The Transformational Effects of COVID-19 on Medical Education. JAMA 324, 1033-1034.

Merrian webster dictionary (2021) Chaos: Meaning and History. Accedido en: https://www.merriam-webster.com/words-at-play/ chaos-meaning-and-history el 21 de Junio de 2021.

Papapanou M, Routsi E, Tsamakis K, Fotis L, Marinos G, Lidoriki I, Karamanou M, Papaioannou TG, Tsiptsios D, Smyrnis N, Rizos E. \& Schizas D. (2021). Medical education challenges and innovations during COVID-19 pandemic. Postgraduate Medical Journal. March 29th postgradmedj-2021-140032. Advance online publication. Accedido en: https:/pmj.bmj.com/content/early/2021/03/28/ postgradmedj-2021-140032.long el 30 de Agosto de 2021.

Puschel K, Repetto P, Bernales M, Barros J, Perez I. \& Snell L. (2017) "In our own words": Defining medical professionalism from a Latin American perspective. Education for Health 30,11-18.

Puschel K, Riquelme A, Moore P, Rojas V, Perry A. \& Sapag JC. (2017) What makes a medical school socially accountable in Latin America? A report from a Latin American panel based on a qualitative approach. Medical Teacher 39, 415-421.

Ritchie J. \& Lewis J. (2003). Qualitative research practice: a guide for social science students and researchers. London: Sage.

Rose S. (2020). Medical Student Education in the Time of COVID-19. JAMA 323, 2131-2132.

Tolu LB, Feyissa GT, Ezeh A. \& Gudu W. (2020). Managing Resident Workforce and Residency Training During COVID-19 Pandemic: Scoping Review of Adaptive Approaches. Advanced Medical Education Practice 11, 527-535.

Trevor G. (2020) The Covid-19 pandemic: Provoking thought and encouraging change, Medical Teacher 7, 738-740. 